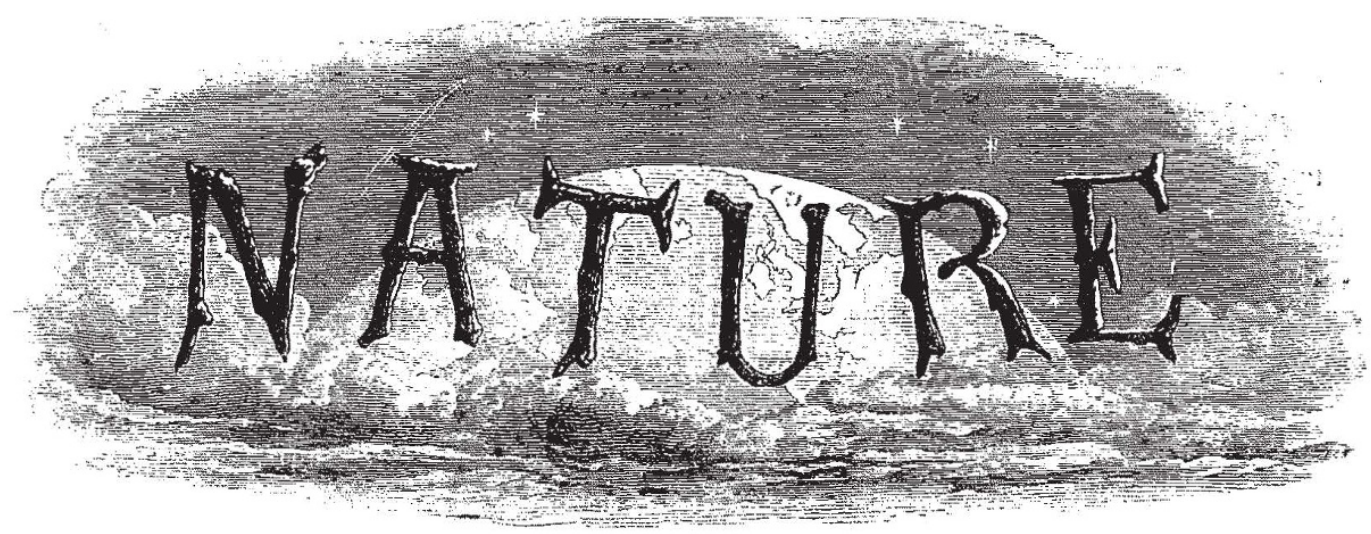

A WEEKLY ILLUSTRATED JOURNAL OF SCIENCE

"To the solid sround"

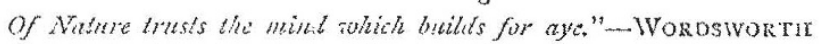

THURSDAY, NOVEMBER 5, IS74

\section{THE PROSPECTS OF THE ENDOWMENT OF RESEARCII}

$W^{1+1}$

ITH this number a new volume of NATURE is commenced, and consequently it will not be inappropriate to take the opportunity of presenting some sort of review of the present position of a subject towards which we have always been ready to devote much of our space. We propose to show that the important evidence given before the Royal Commission on the Advancement of Science, and the Reports which that Commission has already issued, have not been without influence in the mattcr, whilst the publication of the Report of the University Commissioners renders it the more necessary not to relax our efforts in"pressing this question continually upon the public. It is most cncouraging also to notice as another symptom that ordinary opinion is gracluaily coming round to the views we have so long advocated, that the datily and weekly press have during the past month opened their columns to articles and correspondence on this subject, and that journalists no longer regard the proposal to cndow scientific research as a visionary and wild scheme, but now consider it worthy of much consideration and intelligent criticism. Even at the Universities considcrable progress in the right direction seems to have been made, which is the more deserving of attention when it is recollected that the Colleges have in most cases great constitutional difficulties to overcome before that they can carry into cxecution the smallest reform.

At the end of the first volume of the Report of the University Commissioners there is printed in the Appendix a comprehensive scheme for a redistribution of their revenues, which has in principle been unanimously adopted by the governing body of New College, Oxford. It represents a plan of reform, the most fundamental in its principles and the most elaborate in its details which has yet been offered to the public, and shows in all its features how willing the more cnlightened Collegres are to adapt themselves to modern requirements. The date of the adoption of the report of a select committee embody- ing this scheme is October $S, 1873$, and the contents of the report prove no less certainly than the date of its adoption that the labours of the Royal Commission on the Advancement of Science have not been thrown away. "The encouragement of mature learning, as distinct from teaching," is expressly recognised as one of the four objects which College Fellowships should serve ; and accordingly, "this purpose is met by providing for the election to Fellowships, and for the retention in Fellowships, of persons who have given proof of real interest and aptitude in literary or scientific studies." These F cllowships are elsewhere described as "held mercly on the general condition of study," and the election may" be without examination in the case of a person already eminent in literature or science. All the Fellowships to which no educational or bursarial duties are attached are limited to a period of seven years, and the proposed cmolument is 200l. per annum; but "the College shall have power to re-elect once or nore times, for periods of seven years, any Fellow who is engaged in literary or scientific study, which is likely to produce results of permanent value in published writings." These proposals form part of a scheme in which the College committee dispose in various ways of a total annual sum of $16,000 l$., at which amount they estimate thcir divisible revenue at the end of the present century; and though there may be sevcral details in the entire scheme which suggest criticism, yct New College will always deserve a high meed of praise for being the first college to break through the ancient traditions which have hitherto prevented the corporate revenues of these institutions from being directly utilised for objects disconnected with education. The revised statutes of University College, which have been approved by her Majesty in Council, also deserve notice in that they reserve power to the College to elect to a Fellowship without examination "any person of special eminence in literature, science, or art." It is true that this clause is merely a modification of one which already occupies a place in the ordinances of the majority of the Oxford Colleges, which gives the same power, with the proviso that such person shall have received an honorary degree from the Convocation of the University. But as this clause has never yet, to our knowledge, been acted upon, the necessary inference is that the proviso, which 
appears sound in principle; is found in practice an insuperable obstacle. It may here be noticed that the revised statutes of Balliol, to which College the outside world is wont to look as the leader in all reform, ordain that all Fellowships shall be filled up after examination, except only in the case of University Professors, or persons eminently qualified to be college tutors. It does not appear from the Report of the Commission that the Cambridge Colleges have yet taken any steps to appropriate definitely any portion of their endowments to the encouragement of scientific research; but it is a matter of common notoriety that at the October election to Fellowships at Trinity College, a candidate was successful whose chief qualification was that he had already accomplished good original work in embryological investigation; and Cambridge men may therefore boast that this one fact is worth all the schemes of the sister University. Both Oxford and Cambridge, however, will have to do much more than they have yet attempted, or than most of itheir members would appear to have yet conceived, before they can satisfy the public wants and justify the retention of their wealth as it now stands disclosed.

In other respects also we are glad to observe that the objectors to the endowment of research are growing less numerous and less violent, and that the details of a scheme by which this object may be furthered are becoming more acceptable to the general public. The question was brought into prominence by an article in the last number of the Fortnightly Review, and the writer of that article has not been slow to strengthen his positions and answer all opponents in the daily and the weekly press. We must confess that we have been fairly surprised to see with what general acceptance his thoroughooing views have been met, and they merely require the approval of persons eminent in their particular sciences in order that they may carry conviction to all impartial minds. The evening organ of the Conservative party concludes a notice of them with the following judicious sentence, which could not have been written a bare twelvemonth ago:- "The general principle of the need of some sort of endowment for science is generally admitted, and in the main features of the scheme there is much to recommend it to a prudent public." The remaining evening papers, which have all called attention to the scheme, are, if not so laudatory, at least critical rather than hostile; for the time seems to have passed when the matter can be thought deserving of being laughed down with a sncer. We feel bound to refer more particularly to a letter contained in the Spectator of October 24, written by the gentlcman referred to above, and entitled, "A Draft Schcme for Endowing Research." The intention of the letter is to show that it is practicable, by means of a judicious application of precarious salaries, to train up a class of scientific investigators, and that it is a safe investment to give endowments to young men before they have reached eminence in their studies. This point deserves the more attention because it appears to be now widely granted that sinecure posts ought to be provided for men of science who are already famous for their discoveries, and for this latter object the Colleges have at present sufficient power, if only the will also were there. The essence of this draft scheme is to be found in the principle, at once comprehensive and simple, that no candidate is to establish his claim to a permanent endowment until he has previously served an apprenticeship of some ten years, during which period he must furnish continual proofs of his aptitude and diligence, and will receive regular payment by results amounting to a continuous salary if his work is satisfactory. The candidates would be originally selected on the nomination of the professor under whom they have studied, tempered by a moderate examination to exclude manifest incompetence; and during their long period of probation they will be continually liable to rejection, if it be found by the board to which this duty is entrusted that they are not worth the money they are receiving. This plan, no doubt, is well worthy of trial at a central University, where the prolonged course of study under the superintendence of professors naturally lends itself to its adoption, and it could scarcely be perverted to greater wastefulness than at present characterises the Fellowship system at Oxford and Cambridge. It may, however, be plausibly suggested that something less elaborate in system and more closely adapted to the wants of specific studies would be required in the pecuniary encouragement of research which it is the duty of the nation, independently of the Universities, to undertake.

\section{GRESHAM COLLEGE}

$\mathrm{N}$ the previous article we speak of the advancement of of scientific research, and here we wish to refer to an excellent article in Monday's Daily Nerws connected with the advancement of education. The misuse and idleness of the untold wealth of the London City Companies we have frequently referred to ; but until the Daily Ncres unearthed the facts contained in its article, few people were aware of the existence of an institution which is one of the most striking anachronisms of our time, and the uselessness of whose cndowments is provoking, now that the importance of scientific cducation to all classes is beginning to be keenly felt, and when its progress is so much hampered by want of means. The writer in the Daily News deserves the greatest credit for the trouble he must have put himself to in obtaining the facts about the institution known as "Gresham College," and for the uncompromising way in which he has stated the facts of the case. It is indeed a hopeful sign of the recognised importance of sound scientific teaching, when the daily press espouses its cause so heartily.

The Daily News article begins by referring to the admirable system of lectures to working men during the winter at South Kensington in connection with the School of Mines, and which are so popular that many are shut out from want of room in the lecture theatre. Each Professor now gives a course of six lectures in alternate years, an average of twenty-four lectures being thus given in the course of the year, in the plainest English, by Professors of the first rank, for the nominal fee of one penny per lecture. "More thronged, more silent, or more attentive audiences," to quote the Daily Neres article, "than those which attend these lectures to working men it would be impossible to find, even in the halls of the most learned of learned societies." This, combined with the results of some of the examinations in the Science and Art Department, seems to us to prove the readiness and eagerness 